\title{
RN4Cast Study in Portugal: Nurses and care left undone
}

\author{
Clara Braga,' Élvio Jesus, Beatriz Araújo \\ Universidade Católica Portuguesa, Centro de Investigação Interdisciplinar em Saúde, Porto, Portugal
}

Received: February 2, 2018

Accepted: March 24, 2018

Online Published: April 8, 2018

DOI: $10.5430 /$ jha.v7n2p58

URL: https://doi.org/10.5430/jha.v7n2p58

\begin{abstract}
Background: Over the past decades, nursing in Portugal has evolved greatly both academically and professionally and this evolution brought along growing concerns about the quality of the healthcare provided. Due to lack of time or poor organization of the workload, nurses are often faced with the need to choose between what must be done and what will have to be postponed or even not be done at all.

Objective: To investigate the care activities that are most frequently left undone or are postponed by nurses working in medical and surgical inpatient units in Portugal.

Methods: A descriptive, cross-sectional, quantitative study that follows the RN4CAST (Nurse Forecasting in Europe) methodology was carried out from October 2013 to April 2014. A total of 31 hospitals and a random sample of adult medical-surgical units were involved. The data were collected using a socio-demographic questionnaire and a nursing questionnaire that included the identification of the nursing activities of surveillance and direct patient care that were necessary but postponed or not performed by nurses in their most recent shift.

Results: A total of 2,235 nurses participated. Almost all participants had a nursing bachelor degree (98.2\%). The most frequently left undone or postponed care items were "Educating patients and family" (50.2\%) and "Comfort/talk with patients" (50.1\%); the least frequently left undone items were "Treatments and procedures" (3.9\%) and "Pain management" (5.6\%). Nurses in the North and Center regions of the country were the ones who reported less care left undone due to lack of time. Nurses under the age of 40 were those who reported a highest number of activities left undone.

Conclusions: Nurses make selective choices about the care activities that are crucial for the patient. Some activities that may not have an immediate impact on the health of the patients are sidelined, although they may have an impact on other important healthcare quality indicators.
\end{abstract}

Key Words: Care left undone, Nurses, Medical-surgical units, RN4Cast

\section{INTRODUCTION}

The quality of healthcare provided has become a source of concern for many nurses. Nurses know that the planning and implementation of healthcare should be founded on a safe practice that provides all the necessary care to patients. However, investigation and reflection on the practice of nurses has shown that many of the necessary nursing activities are not performed or are postponed. Poor management and work overload are often reported as the reasons given for postponing or not delivering the care.

Kalisch et al. ${ }^{[1]}$ defined missed care as any aspect of the nursing care needed by the patient which is missed or delayed,

\footnotetext{
*Correspondence: Clara Braga; Email: mbraga@porto.ucp.pt; Address: Universidade Católica Portuguesa, Centro de Investigação Interdisciplinar em Saúde, Porto, Portugal.
} 
considering this as a missed care failure.

The literature reveals the terms "Missed care", "Missing care" and "Care left undone", ${ }^{[1,2]}$ but despite this variety and as mentioned by Ausserhofer et al., ${ }^{[3]}$ they all refer to nursing care activities that are partially or totally skipped.

The literature mentions several factors that lead to Nursing Care Left Undone (NCLU), such as the number of hours worked $^{[2,4]}$ or an inadequate hospital organization. ${ }^{[5]}$

In a qualitative study carried out by Kalisch, ${ }^{[6]}$ one of the research issues was the reasons identified by the nurses for not performing certain nursing care activities. Using a focus group, seven items were highlighted: shortage of employees; time required for the nursing task; misuse of existing human resources; "It's not my job" syndrome; inefficient task delegation; habits; and denial of the need to perform the task.

The prevalence, patterns and predictors of NCLU were analyzed in the transversal study Nurse Forecasting: $\mathrm{Hu}$ man Resources Planning in Nursing that was organized by RN4CAST in 12 European countries and covered the period 2009-2011. The RN4Cast "studied how organizational features of hospital care impact on nurse recruitment, nurse retention and patient outcomes"[7] and used a survey. It was funded by the European Commission. ${ }^{[8]}$

The phenomenon of NCLU appears to be common: In the hospitals investigated nurses make decisions about the activities they perform and the ones they skip or delay. Nurses build a list of priority activities that are always carried out and other activities that, because they regard them as less valuable, are more frequently discarded. ${ }^{[3]}$

The activities left undone by nurses are listed by several authors: the two activities most frequently overlooked are "Psychosocial care" and "Paperwork related to care", ${ }^{[3]}$ but this group also includes "Comfort patient" and "Educating patient". ${ }^{[2]}$ On the other hand, activities related to "Physical care" and "Monitoring" are the ones that are less frequently left undone. ${ }^{[3]}$

The literature shows that there is a strong correlation between the phenomena of NCLU and management measures: nursing care left undone are reduced in a practice-friendly environment and with a well trained and professional nursing team. ${ }^{[2,4,9]}$ On the other hand, several studies show that the level of development of the nursing team is a predictive factor for the activities left undone. ${ }^{[10,11]}$

The literature also refers to several NCLU precipitating factors, such as the number of hours worked ${ }^{[2,4]}$ and an inappropriate hospital organization. ${ }^{[9]}$

Published by Sciedu Press
In a South African study including 1,166 nursing professionals, NCLU were considered the major factor of job dissatisfaction. ${ }^{[12]}$

A recently published article ${ }^{[13]}$ analyzed the correlated factors and predictors of NCLU. These were directly related to the type of hospital and units, the age of the participants and their functions, as well as the perception of nurses about the appropriate number of nurses and the type of teamwork.

In a study in Sweden involving 79 hospitals and 10,174 nurses, $74 \%$ of the nurses reported NCLU on the last shift and a significant relationship was found to exist with the shift worked, the type of client, the practice environment, the role of the nurse, and the working team. ${ }^{[14]}$

Some studies point out that the analysis of NCLU can be an important indicator to identify emerging problems prior to the occurrence of serious consequences, thus allowing managers, regulators or others to detect possible problems that may put at risk the lives of the patients. ${ }^{[2]}$

There were found no publications in Portugal on this subject. There are, however, several works in related areas such as the quality of the care provided, job satisfaction, burnout and engagement. It is therefore relevant to carry out this study in order to determine the activities that nurses most frequently leave undone or postpone in medical and surgical inpatient units in Portugal. We have also analyzed the correlation between NCLU and the gender, age and professional training of the nurses, as well as its distribution within the different regions of the country.

\section{MATERial AND METHODS}

The methodology followed was essentially the one defined by the international consortium RN4Cast. ${ }^{[15,16]}$ The nursing survey contained 118 questions comprising nursing work environment, burnout, job satisfaction, nurse-perceived quality of care, nurse staffing levels (number of nurses and level of education), and a demographics section.

The present study analyzed 13 of those questions about NCLU in the last shift completed by nurses, ${ }^{[2,17]}$ as well as the demographics section. The NCLU identified were: adequate patient surveillance; adequate documentation of nursing care; administering medication on time; comfort/talk with patients; develop or update nursing care plans/care pathways; educating patients and/or family; frequent changing of patient's position; oral hygiene; pain management; planning care; preparing patients and families for discharge; skin care; undertaking treatments/procedures. ${ }^{[2]}$

This was a descriptive, cross-sectional, quantitative study involving nurses and users of general hospitals (from the 
public, private or social sector, publicly funded) with more than 100 inpatient beds and a minimum of four medical and/or surgical adult specialties from the various regions of mainland Portugal and from the Autonomous Regions.

\subsection{Sample}

From the 38 organizations that fulfilled the inclusion criteria, a total of 31 hospitals participated in the study (participation rate of $81.6 \%$ ), regardless of their grouping form (Hospital, Hospital Center or hospitals integrated in a Local Health Unit).

Four to six medical and surgical units were randomly selected from each hospital according to their size (4 units if number of beds was below 500; 5 units if number of beds was between 500 and 1,000; and 6 units if number of beds was above 1,000). All nurses and specialist nurses of the selected units were invited to participate in the study by completing a questionnaire. For this study were selected Adult Medical units, Adult Surgical units; and Medical Specialties units like Endocrinology or Neurology and Surgery Specialties units such as Vascular Surgery or Plastic Surgery, and also Mixed Inpatient Units (surgical and medical patients).

\subsection{Organization and data collection}

Each potential participating nurse received a questionnaire validated for the Portuguese culture and an information leaflet containing, an invitation to participate on a voluntary basis, the statement that by completing the survey the participant would be providing consent to participate and an envelope for anonymous and confidential return of the information.

After completing the questionnaire, each nurse was instructed to place it in a closed envelope in a container to be later sent to Universidade Católica Portuguesa (UCP) - where it was subsequently opened.

As in the European study, ${ }^{[3]} 13$ nursing care activities directly related to surveillance and direct patient care were selected, such as "Planning and documenting care" and "Psychosocial care". Each respondent could select more than one item, identifying activities considered necessary by the nurses but left totally or partially undone in their last work shift due to lack of time. ${ }^{[9,17]}$

In the last section, the questionnaire addressed issues directly related to the nurse, including his/her socio-demographic background, such as gender, age, nursing degree, holder or not of a specialty degree, the country of his/her training, the employment status (professional experience, the number of years worked at the present hospital, whether it was a full-time or part-time job, whether the nurse had another part- time job, and whether he/she was satisfied with the job. ${ }^{[3]}$ The regions of the country were identified, as well as the size (number of beds) of the hospitals included in the study.

The data were collected between the last week of October 2013 and the last week of April 2014 in 31 Portuguese hospitals in a total of 144 medical-surgical units. Nurses in each unit were given a timeframe of two weeks to complete and return the questionnaires.

\subsection{Data analysis}

The data was entered into a database created in the software IBM SPSS V22 and resorting to descriptive statistics.

\subsection{Ethical considerations}

The study was approved by the Ethics Committee of UCP and authorized by the boards of directors of the participating hospitals.

\section{RESULTS}

The study included 2,235 nurses out of the 2,905 who were working during the data collection period in the 144 units selected, representing a participation rate of $76.9 \%$.

The majority of the nurses held a bachelor degree $(98.2 \%)$ and $19.3 \%$ had a nursing specialty degree. Respondents were mostly female (80.2\%), worked in medical units $(31.9 \%)$ in hospitals with more than 500 beds belonging to the Northern Regional Health Administration (39.6\%) and one in four nurses also worked in other places (part-time work). The mean age was 34.7 years (SD 8.1 years), had 11.6 years (SD 8 years) of nursing practice and had been working at the hospital in which they answered the questionnaire for 9.8 years (SD 7.6 years) (see Table 1).

\section{Pattern and prevalence of the nursing care left undone}

Table 2 presents the descriptive results referring to the question "In your last shift, which of the following activities were necessary but were not performed due to lack of time"?

From the analysis of the 2,235 questionnaires summarized in Table 2, we found that the items that were less frequently left undone are "Treatments and procedures" (4\%) and "Pain management" (5.7\%). The main nursing activities left undone in the last shift are "Educating patients and family" (50.2\%) and "Comfort/talk with patients" (50.1\%).

It was considered pertinent to verify the difference in the NCLU in variable "Gender" (see Figure 1). 
Table 1. Socio-demographic and professional variables of the participants

\begin{tabular}{|c|c|c|}
\hline Variable & $\mathbf{n}$ & $\%$ \\
\hline \multicolumn{3}{|l|}{ Bachelor Degree in Nursing: } \\
\hline Yes & 2,146 & 98.2 \\
\hline No & 39 & 1.8 \\
\hline \multicolumn{3}{|l|}{ Professional Title: } \\
\hline Nurse & 1,733 & 80.7 \\
\hline Nurse Specialist & 414 & 19.3 \\
\hline \multicolumn{3}{|l|}{ Gender: } \\
\hline Male & 431 & 19.8 \\
\hline Female & 1,746 & 80.2 \\
\hline \multicolumn{3}{|l|}{ Type of Unit: } \\
\hline Medicine & 701 & 31.9 \\
\hline Surgery & 382 & 17.4 \\
\hline Orthopedics & 322 & 14.7 \\
\hline Medical Specialties & 359 & 16.3 \\
\hline Surgery Specialties & 364 & 16.6 \\
\hline Mixte & 69 & 3.1 \\
\hline \multicolumn{3}{|l|}{ Hospital dimension: } \\
\hline Less than 500 beds & 1,101 & 49.3 \\
\hline Equal or more than 500 beds & 1,134 & 50.7 \\
\hline \multicolumn{3}{|l|}{ Working Area (Region): } \\
\hline North & 885 & 39.6 \\
\hline Centre & 288 & 12.9 \\
\hline Lisbon and Tagus Valley & 632 & 28.3 \\
\hline South & 259 & 11.6 \\
\hline Autonomous Regions & 171 & 7.7 \\
\hline \multicolumn{3}{|l|}{ Also working in other places: } \\
\hline Yes & 542 & 24.9 \\
\hline No & 1,631 & 75.1 \\
\hline
\end{tabular}

It was found that, excluding items "Frequent changing of patient position", "Prepare patients and families for discharge" and "Comfort/talk with patients", the other 10 items were identified in a higher percentage by men. The greatest disparity was found in item "Oral hygiene" (5.6\%), with male nurses being the ones who most frequently refer it as a task not carried out $(40.2 \%)$.

The activities that nurses identified as having been postponed were analyzed to see if there were differences between the various age groups (less than 29 , from 30 to 39 , from 40 to 49 , from 50 to 59 and 60 or more years). Results are summarized in Table 3.

The analysis of the data shows that age groups 1 and 2 are the ones that most frequently leave care undone across almost all items, with the exception of the item "Adequately document nursing care", which reaches the greater percentage in age group 5.

We have also checked if there were relevant differences by region of the country, and the data obtained are presented in Table 4.

Azores is the region where nurses most frequently refer care left undone due to lack of time (in 7 items), followed by the Lisbon and Tagus Valley region (in 5 items).

In line with the literature that indicates the level of professional development as a possible factor influencing NCLU, "Adequate patient surveillance" is the second item with the highest percentage difference (4\%) between nurses who have a specialty (30.9\% refer to this item as left undo) and those who do not have a specialty (26.9\%); The highest is "Oral Hygiene" with a 5.8\% difference (see Table 5).

Table 2. Relative descriptive results of the "care left undone"

\begin{tabular}{lll}
\hline Item & \multicolumn{1}{c}{ Answers } \\
\cline { 2 - 3 } & Yes, n (\%) $\mathbf{n}(\%)$ & $1,579(72.3)$ \\
Adequate patient surveillance & $604(27.7)$ & $1,827(83.6)$ \\
Skin care & $358(16.4)$ & $1,412(64.6)$ \\
Oral hygiene & $774(35.4)$ & $2,062(94.3)$ \\
Pain management & $125(5.7)$ & $1,089(49.9)$ \\
Comfort/talk with patients & $1,095(50.1)$ & $1,088(49.8)$ \\
Educating patients and family & $1,097(50.2)$ & $2,097(96.0)$ \\
Treatments and procedures & $87(4.0)$ & $2,053(93.9)$ \\
Administer medications on time & $134(6.1)$ & $1,523(69.7)$ \\
Prepare patients and families for discharge & $662(30.3)$ & $1,579(72.2)$ \\
Adequately document nursing care & $607(27.8)$ & $1,349(61.7)$ \\
Develop or update nursing care plans/care pathways & $838(38.3)$ & $1,733(79.2)$ \\
Planning care & $454(20.8)$ & $1,876(85.8)$ \\
Frequent changing of patient position & $311(14.2)$ & \\
\hline
\end{tabular}




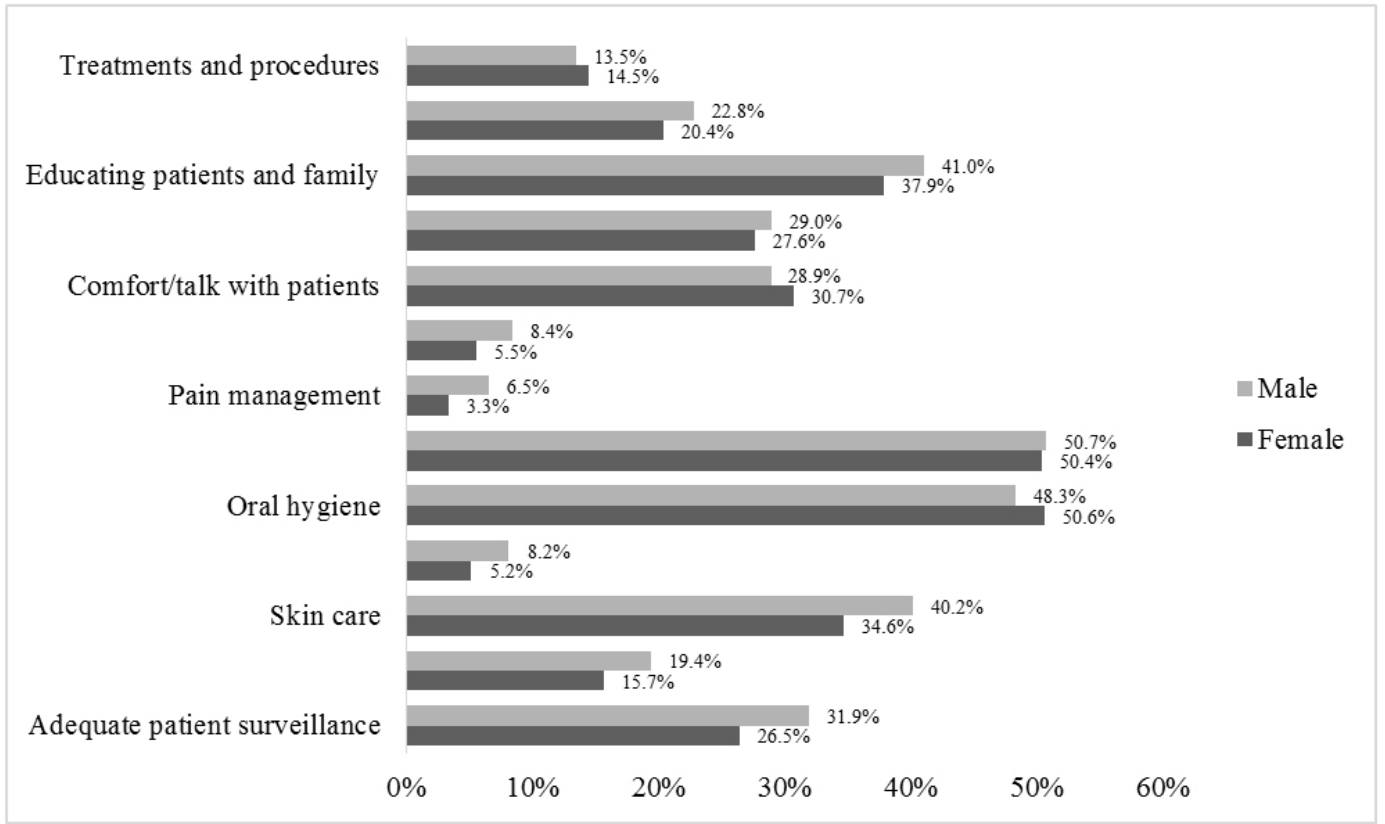

Figure 1. "Care left undone" - percentage distribution by gender

Table 3. Distribution of "care left undone" by age group

\begin{tabular}{|c|c|c|c|c|c|}
\hline \multirow[b]{2}{*}{ Item } & \multicolumn{5}{|c|}{ Age Group } \\
\hline & $\begin{array}{l}<29 \text { years } \\
n=684\end{array}$ & $\begin{array}{l}\text { 30-39 years } \\
n=912\end{array}$ & $\begin{array}{l}40-49 \text { years } \\
n=406\end{array}$ & $\begin{array}{l}50-59 \text { years } \\
n=133\end{array}$ & $\begin{array}{l}60+\text { years } \\
n=7\end{array}$ \\
\hline Adequate patient surveillance & $\begin{array}{l}198 \\
(29.0 \%)\end{array}$ & $\begin{array}{l}259 \\
(28.6 \%)\end{array}$ & $\begin{array}{l}104 \\
(25.8 \%)\end{array}$ & $\begin{array}{l}29 \\
(22.3 \%)\end{array}$ & $\begin{array}{l}1 \\
(16.7 \%)\end{array}$ \\
\hline Skin care & $\begin{array}{l}136 \\
(19.9 \%)\end{array}$ & $\begin{array}{l}138 \\
(15.2 \%)\end{array}$ & $\begin{array}{l}58 \\
(14.4 \%)\end{array}$ & $\begin{array}{l}19 \\
(14.6 \%)\end{array}$ & $\begin{array}{l}1 \\
(16.7 \%)\end{array}$ \\
\hline Oral hygiene & $\begin{array}{l}267 \\
(39.0 \%)\end{array}$ & $\begin{array}{l}338 \\
(37.3 \%)\end{array}$ & $\begin{array}{l}116 \\
(28.8 \%)\end{array}$ & $\begin{array}{l}39 \\
(30.0 \%)\end{array}$ & $\begin{array}{l}0 \\
(0.0 \%)\end{array}$ \\
\hline Pain management & $\begin{array}{l}40 \\
(5.8 \%)\end{array}$ & $\begin{array}{l}56 \\
(6.2 \%)\end{array}$ & $\begin{array}{l}19 \\
(4.7 \%)\end{array}$ & $\begin{array}{l}7 \\
(5.4 \%)\end{array}$ & $\begin{array}{l}0 \\
(0.0 \%)\end{array}$ \\
\hline Comfort/talk with patients & $\begin{array}{l}364 \\
(53.3 \%)\end{array}$ & $\begin{array}{l}474 \\
(52.3 \%)\end{array}$ & $\begin{array}{l}173 \\
(43.0 \%)\end{array}$ & $\begin{array}{l}56 \\
(43.1 \%)\end{array}$ & $\begin{array}{l}1 \\
(16.7 \%)\end{array}$ \\
\hline Educating patients and family & $\begin{array}{l}356 \\
(52.0 \%)\end{array}$ & $\begin{array}{l}468 \\
(51.7 \%)\end{array}$ & $\begin{array}{l}187 \\
(46.5 \%)\end{array}$ & $\begin{array}{l}60 \\
(46.2 \%)\end{array}$ & $\begin{array}{l}3 \\
(50.0 \%)\end{array}$ \\
\hline Treatments and procedures & $\begin{array}{l}22 \\
(3.2 \%)\end{array}$ & $\begin{array}{l}44 \\
(4.9 \%)\end{array}$ & $\begin{array}{l}15 \\
(3.7 \%)\end{array}$ & $\begin{array}{l}4 \\
(3.1 \%)\end{array}$ & $\begin{array}{l}0 \\
(0.0 \%)\end{array}$ \\
\hline Administer medications on time & $\begin{array}{l}47 \\
(6.9 \%)\end{array}$ & $\begin{array}{l}60 \\
(6.6 \%)\end{array}$ & $\begin{array}{l}17 \\
(4.2 \%)\end{array}$ & $\begin{array}{l}8 \\
(6.2 \%)\end{array}$ & $\begin{array}{l}0 \\
(0.0 \%)\end{array}$ \\
\hline Prepare patients and families for discharge & $\begin{array}{l}230 \\
(33.6 \%)\end{array}$ & $\begin{array}{l}279 \\
(30.8 \%)\end{array}$ & $\begin{array}{l}105 \\
(26.1 \%)\end{array}$ & $\begin{array}{l}28 \\
(21.7 \%)\end{array}$ & $\begin{array}{l}2 \\
(33.3 \%)\end{array}$ \\
\hline Adequately document nursing care & $\begin{array}{l}162 \\
(23.7 \%)\end{array}$ & $\begin{array}{l}293 \\
(32.3 \%)\end{array}$ & $\begin{array}{l}107 \\
(26.6 \%)\end{array}$ & $\begin{array}{l}32 \\
(24.8 \%)\end{array}$ & $\begin{array}{l}2 \\
(33.3 \%)\end{array}$ \\
\hline Develop or update nursing care plans/care pathways & $\begin{array}{l}266 \\
(38.9 \%)\end{array}$ & $\begin{array}{l}375 \\
(41.3 \%)\end{array}$ & $\begin{array}{l}107 \\
(35.0 \%)\end{array}$ & $\begin{array}{l}39 \\
(30.0 \%)\end{array}$ & $\begin{array}{l}1 \\
(16.7 \%)\end{array}$ \\
\hline Planning care & $\begin{array}{l}153 \\
(22.4 \%)\end{array}$ & $\begin{array}{l}200 \\
(22.1 \%)\end{array}$ & $\begin{array}{l}76 \\
(18.9 \%)\end{array}$ & $\begin{array}{l}19 \\
(14.6 \%)\end{array}$ & $\begin{array}{l}0 \\
(0.0 \%)\end{array}$ \\
\hline Frequent changing of patient position & $\begin{array}{l}114 \\
(16.7 \%)\end{array}$ & $\begin{array}{l}127 \\
(14.0 \%)\end{array}$ & $\begin{array}{l}55 \\
(13.6 \%)\end{array}$ & $\begin{array}{l}12 \\
(9.2 \%)\end{array}$ & $\begin{array}{l}0 \\
(0.0 \%)\end{array}$ \\
\hline
\end{tabular}


Table 4. Descriptive results regarding items of "care left undone" by region of the country

\begin{tabular}{|c|c|c|c|c|c|c|}
\hline \multirow[b]{2}{*}{ Item } & & \multicolumn{5}{|c|}{ Region } \\
\hline & & $\begin{array}{l}\text { Northern } \\
(\%)\end{array}$ & $\begin{array}{l}\text { Center } \\
(\%)\end{array}$ & $\begin{array}{l}\text { Lisbon \& Tagus } \\
\text { Valley }(\%)\end{array}$ & $\begin{array}{l}\text { Southern } \\
(\%)\end{array}$ & $\begin{array}{l}\text { Autonomous } \\
\text { Regions (\%) }\end{array}$ \\
\hline \multirow{2}{*}{ Adequate patient surveillance } & Yes & 23.8 & 31.4 & 28.7 & 28.9 & 35.5 \\
\hline & No & 76.2 & 68.6 & 71.3 & 71.1 & 64.5 \\
\hline \multirow{2}{*}{ Skin care } & Yes & 16.5 & 17.0 & 16.3 & 17.4 & 14.0 \\
\hline & No & 83.5 & 83.0 & 83.7 & 82.6 & 86.0 \\
\hline \multirow{2}{*}{ Oral hygiene } & Yes & 35.0 & 35.0 & 36.1 & 34.5 & 36.8 \\
\hline & No & 65.0 & 65.0 & 63.9 & 65.5 & 63.2 \\
\hline \multirow{2}{*}{ Pain management } & Yes & 4.3 & 7.2 & 6.3 & 5.9 & 8.2 \\
\hline & No & 95.7 & 92.8 & 93.7 & 94.1 & 91.8 \\
\hline \multirow{2}{*}{ Comfort/talk with patients } & Yes & 47.2 & 50.5 & 55.9 & 49.0 & 45.0 \\
\hline & No & 52.8 & 49.5 & 44.1 & 51.0 & 55.0 \\
\hline \multirow{2}{*}{ Educating patients and family } & Yes & 44.8 & 44.8 & 57.7 & 56.1 & 50.3 \\
\hline & No & 55.2 & 55.2 & 42.3 & 43.9 & 49.7 \\
\hline \multirow{2}{*}{ Treatment and procedures } & Yes & 3.5 & 4.3 & 4.2 & 3.2 & 6.4 \\
\hline & No & 96.5 & 95.7 & 95.8 & 96.8 & 93.6 \\
\hline \multirow{2}{*}{ Administer medications on time } & Yes & 5.0 & 4.3 & 8.2 & 6.3 & 7.0 \\
\hline & No & 95.0 & 95.7 & 91.8 & 93.7 & 93.0 \\
\hline \multirow{2}{*}{ Prepare patients and families for discharge } & Yes & 25.0 & 27.1 & 37.8 & 33.2 & 30.6 \\
\hline & No & 75.0 & 72.9 & 62.2 & 66.8 & 69.4 \\
\hline \multirow{2}{*}{ Adequately document nursing care } & Yes & 27.8 & 24.6 & 31.0 & 20.6 & 31.6 \\
\hline & No & 72.2 & 75.4 & 69.0 & 79.4 & 68.4 \\
\hline \multirow{2}{*}{$\begin{array}{l}\text { Develop or update nursing care plans/care } \\
\text { pathways }\end{array}$} & Yes & 38.6 & 31.0 & 40.1 & 34.0 & 48.5 \\
\hline & No & 61.4 & 69.0 & 59.9 & 66.0 & 51.5 \\
\hline \multirow{2}{*}{ Planning care } & Yes & 18.1 & 20.9 & 23.6 & 19.0 & 26.3 \\
\hline & No & 81.9 & 79.1 & 76.4 & 81.0 & 73.7 \\
\hline \multirow{2}{*}{ Frequent changing of patient position } & Yes & 8.8 & 13.0 & 23.3 & 13.8 & 11.1 \\
\hline & No & 91.2 & 87.0 & 76.7 & 86.2 & 88.9 \\
\hline
\end{tabular}

Table 5. Distribution of "care left undone" according to the level of professional development specialty

\begin{tabular}{lll}
\hline \multirow{2}{*}{ Item } & \multicolumn{2}{c}{ Do you have a Nursing Specialty? } \\
\cline { 2 - 3 } & Yes (\%) & No (\%) \\
\hline Adequate patient surveillance & 30.9 & 26.9 \\
Skin care & 17.3 & 16.3 \\
Oral hygiene & 30.9 & 36.7 \\
Pain management & 7.1 & 5.5 \\
Comfort/talk with patients & 49.9 & 50.2 \\
Educating patients and family & 49.0 & 50.6 \\
Treatments and procedures & 5.4 & 3.6 \\
Administer medications on time & 6.8 & 5.9 \\
Prepare patients and families for discharge & 30.2 & 30.2 \\
Adequately document nursing care & 31.1 & 27.1 \\
Develop and update nursing care plans/care pathways & 39.9 & 38.3 \\
Planning care & 19.2 & 21.4 \\
Frequent changing of patient position & 13.4 & 4.6 \\
\hline
\end{tabular}


Table 6. Comparison of the descriptive results regarding "care left undone" in Portugal and in two other studies

\begin{tabular}{lccc}
\hline \multirow{2}{*}{ Item } & Portugal & Ausserhofer et al. ${ }^{[3]}$ & Ball et al. $^{[14]}$ \\
\cline { 2 - 4 } & $\boldsymbol{\%}$ & \% & 26 \\
\hline Educating patients and family & 50.2 & 40.6 & 46 \\
Comfort/talk with patients & 50.1 & 41.7 & 34 \\
Develop or update nursing care plans/care pathways & 38.3 & 34.4 & 31 \\
Oral hygiene & 35.4 & 22.4 & 16 \\
Prepare patients and family for discharge & 30.3 & 27.5 & 25 \\
Adequately document nursing care & 27.8 & 27.2 & 20 \\
Adequate patient surveillance & 27.7 & 25.8 & 11 \\
Planning care & 20.8 & 24.5 & 25 \\
Skin care & 16.4 & 24.7 & 20 \\
Frequent changing of patient position & 14.2 & 19.4 & 25 \\
Administer medications on time & 6.1 & 10 & 6 \\
Pain management & 5.7 & 9.2 & 6 \\
Treatment and procedures & 4 & & \\
\hline
\end{tabular}

We compared our study with two European studies. ${ }^{[3,14]}$ The Ausserhofer et al. ${ }^{[3]}$ study was carried out in 12 European countries and the second in Sweden. The results of the comparison are listed in Table 5. The item "Educating patients and family" is the task with the greatest amplitude of results $(24.2 \%)$ between our study $(50.2 \%)$ and the Ball et al. ${ }^{[14]}$ study (26\%) (see Table 6).

These results show that, with the exception of the item "Oral hygiene", all the other activities related to direct care to patients are less frequently left undone in the Portuguese study than in the two other studies.

In a direct comparison between the Portuguese and the Ausserhofer et al. ${ }^{[3]}$ study, the item with the largest variation is "Administer medication on time" (6.1 and 19.4, respectively). When comparing the Portuguese and the Ball et al. ${ }^{[14]}$ studies, "Pain management" is the activity with the lowest difference $(0.3 \%)$. On the other hand of the spectrum is the activity "Educating patients and family" (24.2\%).

\section{Discussion}

When managing care activities and prioritizing activities, Portuguese nurses give priority to interdependent activities. This is in line with what is argued in the Ausserhofer et al. ${ }^{[3]}$ study: nurses, based on their assessment of the immediate risk and their general concerns about the well-being of their patients, seem to make important decisions about which nursing care they can omit.

On the other hand, autonomous nursing activities, such as educating and comforting the patient, are identified more frequently as left undone, which is in accordance with other studies. ${ }^{[5,10,18]}$ However, we find the fact that in Portugal these values are are higher than $50 \%$ particularly worrying. This means that, when patients require these care activities, in more than half times they are not performed, which we consider to be at odds with any health quality policy that places the well-being of the patients at the center of its concerns.

When comparing this study with the two other European studies, ${ }^{[3,14]}$ it was noticed that in the Portuguese study direct care to the patient is less delayed or frequently left undone than in the other two studies. Since nurses in Portugal seem to place more emphasis on the immediate physical care activities, such as treatments and procedures, pain management and the administration of the therapy, this may reflect a greater concern for patient safety while in the hospital.

It is also observed that nurses under the age of 40 are the ones who most frequently report having postponed or left undone nursing activities due to lack of time. In the study of Bragadóttir et al., ${ }^{[13]}$ the younger groups are also the ones that report more NCLU. There were differences between Gender in our study, like in Kalisch's study. ${ }^{[10]}$ However, in the Kalisch study were women who most NCLUs identified and in this study were men.

Almost all Portuguese nurses have a bachelor degree (98.2\%), which may also lead them to assign higher value as NCLU to the autonomous areas of nurse intervention (educating, comforting).

In other study, Kalisch et al. ${ }^{[18]}$ concluded that nurses identify more NCLU when their level of academic qualification is higher. Several studies highlight the importance of the level 
of qualification and adequacy of the nursing team to a consistent provision of care to each patient. Furthermore, studies also point out that professional development has an impact on the mortality indicator and on errors by omission, ${ }^{[18-20]}$ including a decrease in the number of patients who suffer falls. ${ }^{[11]}$

In the interventions performed by nurses, activities such as planning care or updating care plans are still relegated to second place, and they tend to favor those that are most directly related to the safety of the patient.

Nursing records have been given special attention in Portugal, by encouraging the use of the CIPE ${ }^{\circledR}$ language and reaffirming the need to create indicators for both the process and the outcome that demonstrate the work performed by the nurses.

However, the analysis of these data shows that there are clear discrepancies between the different regions of the country, the Northern and the Center regions being the ones in which the percentage of NCLU is lower. Other subjects have also been object of study, such as nursing staffing, leading to the conclusion that it is related, for example, with the increase in the readmission rate.

According to the study conducted by Lucero et al., ${ }^{[5]}$ care activities left undone may be the cause of an increase in the number of adverse events. In fact, understanding the impact of NCLU on patient outcomes and job satisfaction may facilitate the development of new strategies to improve the quality of the care provided in hospitals. ${ }^{[21]}$

Regarding documenting nursing care, we share Lang et al. ${ }^{[22]}$ opinion that problems that are not documented in the care process tend to be left out from the nurses' intervention.

\section{Conclusions}

Some of the findings of this study such as the gender and regional differences, need other type of studies to be better understood.

However, there is a long way to go to ensure that the patient gets the best care possible and that the nurse works in an environment that favours the delivery of quality care. Some studies point out that the analysis of NCLU due to lack of time can be an important indicator to identify emerging problems prior to the occurrence of serious consequences, thus allowing managers, regulators or others to detect possible problems that may put at risk the lives of the patients. ${ }^{[2,23]}$ It is also important to check the link between NCLU and cost-benefits and outcomes for the patients. ${ }^{[24]}$

If, on one hand, it seems obvious that work overload may result in activities that are not performed by nurses, on the other hand, other factors such as professional development, staff involvement, teamwork, work engagement, burnout and social representation of the profession need to be further studied.

A culture of quality and safety should be instilled to ensure detailed attention when documenting nursing care so that any failures are honestly reported.

Certain limitations of the study were recognized, highlighting the fact that were used a descriptive, cross-sectional, quantitative study with a self-reported questionnaire.

\section{CONFlicts OF InTEREST Disclosure}

The authors declare that there were no external sources of financing and that there is no conflict of interest regarding the present work.

\section{REFERENCES}

[1] Kalisch BJ, Landstrom GL, Hinshaw AS. Missed nursing care: a concept analysis. Journal of Advanced Nursing. 2009; 65(7): 15091517. PMid: 19456994 . https://doi.org/10.1111/j.1365-2 $648.2009 .05027 . \mathrm{x}$

[2] Ball JE, Murrells T, Rafferty AM, et al. 'Care left undone' during nursing shifts: associations with workload and percieved quality of care. BMJ Quality and Safety. 2014; 23(2): 116-25. PMid: 23898215. https ://doi.org/10.1136/bmjqs-2012-001767

[3] Ausserhofer D, Zander B, Busse R, et al. Prevalence, patterns and predictors of nursing care left undone in European hospitals: results from the multicountry cross-sectional RN4CAST study. BMJ Quality and Safety. 2014; 23: 126-135. PMid: 24214796. https: //doi.org/10.1136/bmjqs-2013-002318

[4] Sochalski J. Is More Better? - The relationship between nurse staffing and the quality of nursing care in Hospital. Medical Care. 2004 Feb,

\section{2 suppl: $67-73$}

[5] Lucero RJ, Lake ET, Aiken LH. Variations in nursing care quality across hospitals. Journal of Advance Nursing. 2009; 65(11): 22992310. PMid: 19737326. https://doi.org/10.1111/j.1365-2 $648.2009 .05090 . x$

[6] Kalisch BJ. Missed Nursing Care, A Qualitative Study. Journal of Nursing Care Quality. 2006; 21(4): 306-313. PMid:16985399. https://doi.org/10.1097/00001786-200610000-00006

[7] RN4Cast. About RN4Cast. 2018. Available from: http://www.rn 4cast.eu/about1.html

[8] Aiken LH, Sloane DM, Bruyneel L, et al. Nurse staffing and education and hospital mortality in nine European countries: a retrospective observational study. The Lancet. 2014; 383(9931): 1824-1830. https://doi.org/10.1016/S0140-6736(13)62631-8

[9] Lucero RJ, Lake ET, Aiken LH. Nursing care quality and adverse events in US hospitals. Journal of Clinical Nursing. 2010; 19: 2185- 
2195. PMid: 20659198. https://doi.org/10.1111/j.1365-2 $702.2010 .03250 . \mathrm{x}$

[10] Kalisch BJ, Tschannen D, Lee H, et al. Hospital Variation in Missed Nursing Care. American Journal of Medical Quality. 2011; 26(4): 291-299. PMid: 21642601. https://doi.org/10.1177/106286 0610395929

[11] Kalisch BJ, Tschannen D, Lee KH. Missed Nursing Care, Staffing and Patient Falls. Journal of Nursing Care Quality. 2012; 27: 612. PMid: 21738057 . https://doi.org/10.1097/NCQ.0b013e $318225 a a 23$

[12] Bekker M, Coetzee SK, Klopper HC, et al. Non-nursing tasks, nursing tasks left undone and job satisfaction among professional nurses in South African hospitals. Journal of Nursing Management. 2015; 23: 1115-1125. PMid: 25345386. https://doi.org/10.1111/ jonm. 12261

[13] Bragadóttir H, Kalisch BJ, Tryggvadóttir GB. Correlates and predictors of missed nursing care in hospitals. Journal Clinical Nursing. 2016; 26: 1524-1534. PMid: 27325454. https ://doi.org/10.1 111/jocn. 13449

[14] Ball JE, Griffiths P, Rafferty AM, et al. A cross-sectional study of "care left undone" on nursing shifts in hospitals. Journal of Advanced Nursing. 2016 Jan; 72(9): 1-12. PMid: 27095463. https: //doi.org/10.1111/jan.12976

[15] Sermeus W, Aiken LH, Heede KVD, et al. Nurse forecasting in Europe (RN4CAST): Rationale, design and methodology. BMC Nursing. 2011; 10(6): 1-9. https://doi.org/10.1186/1472-6 955-10-6

[16] Pinto AM, Jesus E, Mendes AM, et al. Estudo RN4Cast em Portugal: Work Engagement dos Enfermeiros. [ed]. FORMASAU. Revista de Investigação Enfermagem. 2015; 10(2): 26-37.
[17] Schubert M, Glass TR, Clarke SP, et al. Rationing of nursing care and its relationship to patient outcomes: the Swiss extension of the International Hospital Outcomes Study. International Journal for Quality in Health. 2008; 20(4): 227-237. PMid: 18436556. https://doi.org/10.1093/intqhc/mzn017

[18] Kalisch BJ, Landstrom G, Williams RA. Missed nursing care: Errors of omission. Nursing Outlook. 2009; 57: 3-9. PMid: 19150261. https://doi.org/10.1016/j.outlook.2008.05.007

[19] Aiken LH, Clarke SP, Cheung RB, et al. Educational levels of hospital nurses and surgical patient mortality. JAMA. 2003 Sept 24; 290(12): 1617-1623. PMid: 14506121. https ://doi.org/10.1001/jama .290 .12 .1617

[20] Kalisch BJ, Tschannen D, Lee KH. Do staffing levels predict missed nursing care? International Journal for Quality in Health Care. 2011; 1-7. https://doi.org/10.1093/intqhc/mzr009

[21] Tschannen D, Kalisch BJ, Lee KH. Missed Nursing Care: The impact on Intention to Leave and Turnover. Canadian Journal of Nursing Research. 2010; 42(4): 22-39. PMid: 21319636.

[22] Lang TA, Hodge M, Olson V, et al. Nurse-Patient Ratios: A Systematic Review on the Effects of Nurse Staffing on Patient, Nurse Employee, and Hospital Outcomes. JONA. 2004 Jul-Aug; 34(7/8): 326-337. https://doi.org/10.1097/00005110-200 407000-00005

[23] Ball JE, Bruyneel L, Aiken LH, et al. Post-operative mortality, missed care and nurse staffing in nine countries: A cross-sectional study. International Journal of Nursing Studies. 2017; 1-6.

[24] Kalisch BJ, McLaughlin M, Dabney BW. Patient Perceptions of Missed Nursing Care. Joint Comission Journal on Quality and Patient Safety. 2012; 38(4): 161-167. https://doi.org/10.1016/ S1553-7250 (12) 38021-5 